Article

\title{
Dynamic Compression Characteristics and Failure Mechanism of Water-Saturated Granite
}

\author{
Ke Man ${ }^{1}$, Xiaoli Liu ${ }^{2} *\left(\mathbb{D}\right.$, Zhifei Song ${ }^{1}$, Zongxu Liu ${ }^{1}$, Ruilin Liu ${ }^{1}$, Liwen $\mathrm{Wu}^{1}$ and Zixiang Cao ${ }^{1}$ \\ 1 School of Civil Engineering, North China University of Technology, Beijing 100144, China; \\ man_ke@sina.cn (K.M.); songzf@ncut.edu.cn (Z.S.); liuzongxu0127@163.com (Z.L.); \\ liuruilin_ncut@163.com (R.L.); wuliwen_ncut@163.com (L.W.); cao_zixiang@163.com (Z.C.) \\ 2 State Key Laboratory of Hydroscience and Hydraulic Engineering, School of Civil Engineering, \\ Tsinghua University, Beijing 100084, China \\ * Correspondence: xiaoli.liu@tsinghua.edu.cn; Tel.: +86-138-1180-4855
}

check for updates

Citation: Man, K.; Liu, X.; Song, Z.; Liu, Z.; Liu, R.; Wu, L.; Cao, Z.

Dynamic Compression

Characteristics and Failure

Mechanism of Water-Saturated

Granite. Water 2022, 14, 216.

https://doi.org/10.3390/w14020216

Academic Editor: Akbar Javadi

Received: 31 October 2021

Accepted: 3 January 2022

Published: 12 January 2022

Publisher's Note: MDPI stays neutral with regard to jurisdictional claims in published maps and institutional affiliations.

Copyright: (c) 2022 by the authors. Licensee MDPI, Basel, Switzerland. This article is an open access article distributed under the terms and conditions of the Creative Commons Attribution (CC BY) license (https:// creativecommons.org/licenses/by/ $4.0 /)$.

\begin{abstract}
For Fangshan granite in Beijing, the static compression and dynamic compression tests have been carried out separately under natural air drying and water saturation. It was found that the dynamic compressive strength of water-saturated granite is higher than that of air-dried granite, which is contrary to the result that the strength of water-saturated rock is lower than that of air-dried granite under static load. Furthermore, under the medium strain rate condition, when the strain rate is $85 \mathrm{~s}^{-1}$, the dynamic strength of natural air-dried granite could be increased by nearly 0.5 times compared with its static state. The dynamic strength of water-saturated granite could be increased by nearly 1-2 times compared with its static strength, which shows that water-saturated granite has stronger strain rate sensitivity than natural air-dried granite. Meanwhile, under impact loading, from the perspective of water-bearing granite the Bernoulli effect of fluid, the adhesion effect of free water and the Stefan effect of fluid in water-saturated granite were revealed, and found to be the essential reasons affecting the dynamic strength of water-saturated granite. The dynamic strength in different water-bearing states in the range of medium strain rate could then be analyzed in depth, providing a certain reference value for the strength design of water-bearing rock engineering.
\end{abstract}

Keywords: air dried granite; dynamic compression characteristics; rock dynamics; water effect; water saturated granite

\section{Introduction}

Water, as a common fluid in nature, often affects the stability of dams, underground caverns and rock slopes on rock foundations and so on. Natural seismic research related to water is a hot issue, such as tides, waves and reservoir water injection caused by waterinduced rock deformation and damage [1]. The damage, failure and stability of a rock mass under the interaction of water seepage and stress are common concerns of engineering disciplines. Rock mass is often in a water-saturated state, and the mechanical response of rock in a water-saturated state has attracted extensive attention. The influence of water content on different rock acoustic parameters has been studied [2-4]. The saturated sandstone and marble were further studied under the strain rate of $10^{-5} \mathrm{~s}^{-1}$ [5]. Compressive strength changes of saturated concrete under strain rates of $10^{-6}$ and $10^{-4} \mathrm{~s}^{-1}$ have been compared. Dynamic compressive strength of saturated concrete increases under fast loading and decreases under slow loading [6]. Through the uniaxial loading test of air-dried and water-saturated red soft rock, the mechanical action of pore water and the discharge process of pore water have been verified [7]. The anisotropy of water-saturated sandstone and marble with strain rates of $10^{-5}, 10^{-3}$ and $10^{-2} \mathrm{~s}^{-1}$ has been compared [8]. Although these research of water-saturated rock, it is just on water-saturated rock and is limited to the quasi-static situation. While important projects such as actual dams or underground 
caverns often bear the explosion load during the impact or blasting excavation, which involves the variation law of dynamic failure strength of water-saturated rock.

Geological disaster phenomena such as earthquakes, landslides and rock bursts are related to rock fracture, in which the stress wave propagation under stress pulse or impact loading. Relevant prevention and control fields are related to the dynamic mechanical properties, especially rock quasi-brittle materials [8,9]. The loading state could be classified based on the strain rate during loading. The static load can be realized by an ordinary hydraulic servo testing machine, and the dynamic load is generally realized by a split Hopkinson pressure bar (SHPB). There are many studies on the rock mechanical properties under pure dynamic state [10-12], including the constitutive relationship, impact strength, energy dissipation, waveform, strain rate, failure criterion, temperature factor, etc., but there are few studies on the dynamic mechanical properties under water saturation state. The dynamic tensile strength of dry and water-saturated granite has been tested by a Hopkinson compression bar test, which shows that water-saturated granite is more difficult to pull apart than dry granite $[13,14]$. The propagation characteristics of an explosion stress wave in water-saturated rock have been studied by numerical simulation [15]. The dynamic damage of saturated cement specimens under the action of underwater explosion shock wave has been studied [16]. The dynamic mechanical properties of rock under water saturation needs to be further studied in detail, which is of great significance to reveal the occurrence mechanism and prevent engineering rock mass disasters in a water environment.

In this paper, Beijing Fangshan granite was taken as the research object. The impact compression test under water-saturated conditions was carried out on the SHPB test system with the same bar diameter of $75 \mathrm{~mm}$ by using the half sine wave loading mode, in which the incident stress wavelength was proportional to the length of the rock specimen. The main purpose of these experiments was to explore the difference of mechanical properties between water-saturated granite and air-dried granite, as well as the physical mechanism of these phenomena.

\section{Test Method and Technology}

\subsection{Dynamic Test Equipment}

The SHPB test device with a bar diameter of $75 \mathrm{~mm}$ used here was designed and improved by Central South University. It was suitable for the characteristics of medium strain rate loading for rock heterogeneous brittle materials, as elaborated in Figure 1. The schematic of the SHPB equipment is shown in Figure 2.
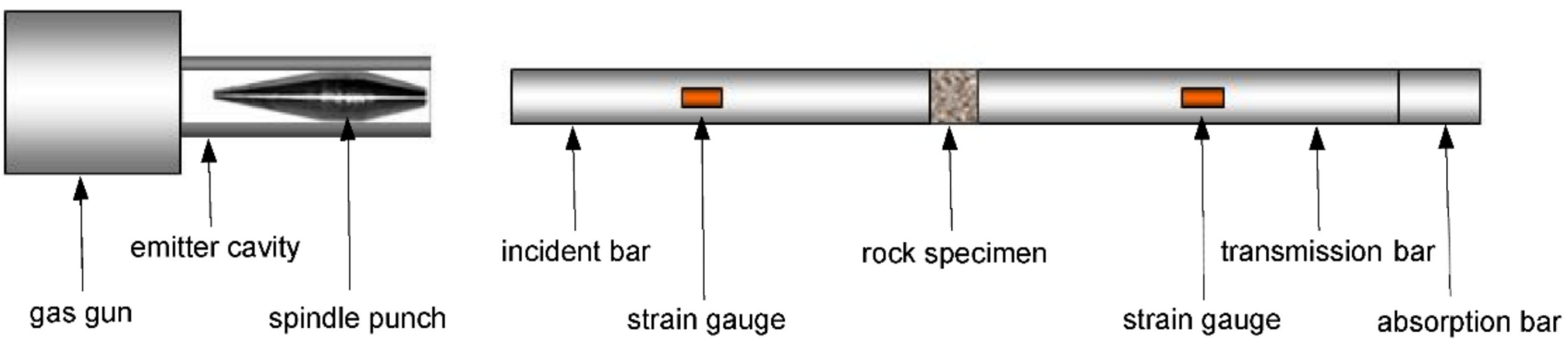

Figure 1. Sketch of split Hopkinson pressure bar (SHPB) setup. 


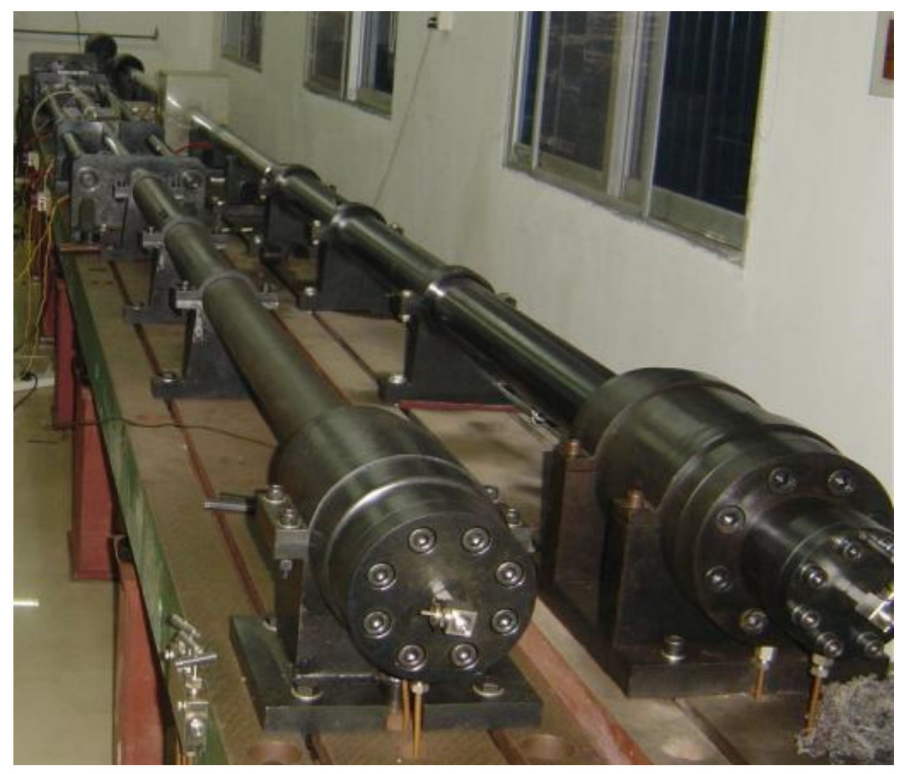

Figure 2. Schematic of SHPB equipment.

The incident bar, transmission bar, absorption bar and punch of the SHPB test device were made of $40 \mathrm{Cr}$ alloy steel; the density was $7810 \mathrm{~kg} \mathrm{~m}^{-3}$, the longitudinal wave velocity was $5400 \mathrm{~m} \mathrm{~s}^{-1}$, the strain gauge attached to the incident bar and transmission bar was B1202AA, the data acquisition was through an CS-1D ultra dynamic strain gauge and DL-750 oscilloscope, and the data processing adopted the system data processing software CLRM independently developed based on the Visual C++ platform. Half sine stress wave loading is realized by using a special-shaped punch. The parameters of the SHPB equipment are shown in Table 1.

Table 1. Parameters of SHPB.

\begin{tabular}{cccccccc}
\hline $\begin{array}{c}\text { Diameter of } \\
\text { the Bar/mm }\end{array}$ & $\begin{array}{c}\text { Length of } \\
\text { the Input } \\
\text { Bar/mm }\end{array}$ & $\begin{array}{c}\text { Length of } \\
\text { the Output } \\
\text { Bar/mm }\end{array}$ & $\begin{array}{c}\text { Elastic Mod- } \\
\text { ulus/GPa }\end{array}$ & $\begin{array}{c}\text { Longitudinal } \\
\text { Wave } \\
\text { Velocity }\end{array}$ & $\begin{array}{c}\text { Poisson } \\
\text { Ratio }\end{array}$ & Pressure/MPa & Density/kg.m $\mathbf{m}^{-3}$ \\
\hline 75 & 2000 & 2000 & 250 & 5400 & 0.285 & $0 \sim 10$ & 7810 \\
\hline
\end{tabular}

According to the one-dimensional stress wave assumption and the uniform distribution of internal stress assumption $[17,18]$, through the dynamic force balance verification of the experimental data, the data obtained are effective and reliable. The equation of the two waves method can be used to process the data, and it is considered that the force on the end face of the specimen is approximately equal.

Using the characteristic that the elastic wave under one-dimensional stress has no distortion when propagating in a slender bar, the dynamic mechanical parameters stress, strain rate and strain of the specimen could be calculated indirectly by measuring the voltage attached to the strain gauge of the incident bar and the transmission bar. The calculation formulas are as follows,

$$
\begin{gathered}
p_{1}(t)=E A\left[\varepsilon_{\mathrm{I}}(t)+\varepsilon_{\mathrm{R}}(t)\right] \\
p_{2}(t)=E A \varepsilon_{\mathrm{T}}(t) \\
u_{1}(t)=c_{0} \int_{0}^{t}\left[\varepsilon_{\mathrm{I}}(t)+\varepsilon_{\mathrm{R}}(t)\right] \mathrm{d} t \\
u_{2}(t)=c_{0} \int_{0}^{t} \varepsilon_{\mathrm{T}}(t) \mathrm{d} t
\end{gathered}
$$


where, $E$ is the elastic modulus of the bar, $A$ is the cross-sectional area of the bar. And $c_{0}$ is the elastic wave velocity in the bar, $\varepsilon_{\mathrm{I}}(t)$ is the incident strain signal of the left end face of the specimen, $\varepsilon_{\mathrm{R}}(t)$ is the reflected strain signal of the left end face of the specimen, and $\varepsilon_{\mathrm{T}}(t)$ is the transmitted strain signal of the right end face of the specimen.

According to the assumption of SHPB homogenization, the stress of the specimen is,

$$
p(t)=\frac{p_{1}(t)+p_{2}(t)}{2}
$$

\subsection{Preparation of Water-Saturated Rock Specimens}

The collected rock was gray and had a medium-grained porphyritic texture. To evaluate the geological nature of the rock, an analysis was conducted using an optical microscope and a scanning electron microscope (SEM). The dominant minerals in the rock were exposed to cross-polarized light for identification. A microscopic view of a thin section of the rock is presented in Figure 3. It was found that quartz, alkaline feldspar, plagioclase, and biotite were the major rock constituent minerals. In addition, SEM observations showed that the rock had a dense texture [19].
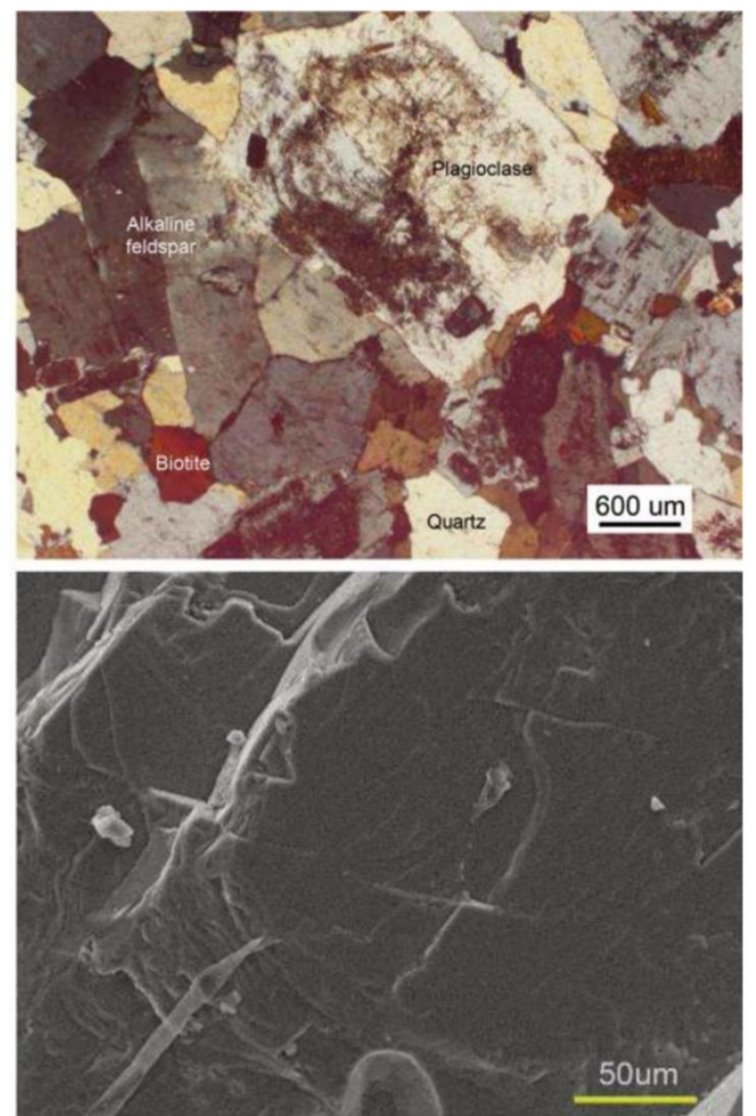

Figure 3. Observations of medium-grained monzogranite at different scales.

Based on the regulations of rock test codes for water resources and hydropower engineering (SL264-2001) [20], the specimen should be forcibly saturated by boiling or vacuum pumping methods. The boiling time should not be less than $6 \mathrm{~h}$, the pumping vacuum degree should reach the negative pressure of $100 \mathrm{kPa}$, and the pumping time should not be less than $4 \mathrm{~h}$. The vacuum pumping method cannot make the dense rock reach the saturation state. The duration of the vacuum pumping method should take thousands of hours, and it is considered that water saturation refers to the maximum water absorption of rock under specific conditions. In addition, this determined that the temperature has a great impact on the physical and mechanical properties of rock. A long period of boiling 
temperature may cause some damage to the rock, leading to a difference of rock mechanical properties. Therefore, the boiling method is also inappropriate. These forced saturation methods are rarely encountered in field practice, and free water absorption is the main way for rocks to reach saturation. In this paper, the water-saturated specimen is mainly prepared according to the free water absorption method in the code for rock tests of water resources and hydropower engineering (SL264-2001). The processed granite specimens are show in Figure 4. Considering that natural air-dried rock is common in engineering practice, the mechanical properties of water-saturated specimens and natural air-dried specimens are compared and analyzed separately.
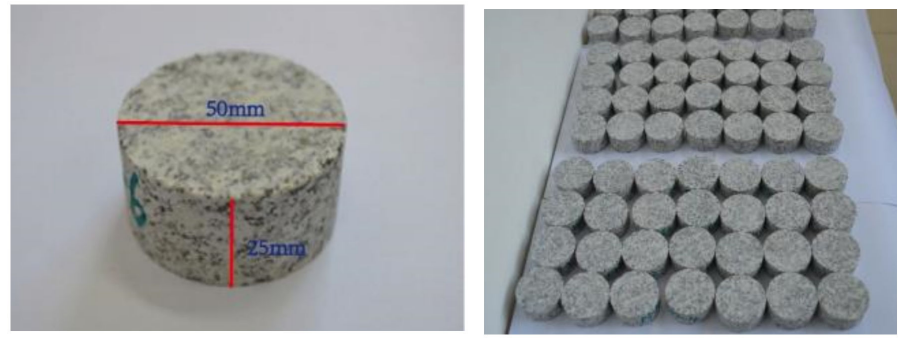

Figure 4. Processed granite specimens.

Granite specimens have been prepared corresponding to static mechanical and dynamic impact tests. According to the requirements of a static mechanical test, the static specimen is processed into a $\Phi 50 \mathrm{~mm} \times \mathrm{H} 100 \mathrm{~mm}$ cylinder, in which the surface parallelism of both ends is within $0.05 \mathrm{~mm}$, and the surface flatness is within $0.02 \mathrm{~mm}$. In the impact test, in order to eliminate the inertia effect and end effect of the specimen, when the inertia effect is 0 , the length diameter ratio of the specimen is about $3 / 2$, so the length diameter ratio of the impact specimen is controlled at about 0.5 . The dynamic specimen is processed into a size of $\Phi 75 \mathrm{~mm} \times \mathrm{H} 37.5 \mathrm{~mm}$ disc. The surface parallelism and flatness are the same as those of a conventional static specimen.

In order to ensure the two-length diameter ratio rocks have a better water saturation effect, after the processed specimen was naturally air-dried, combined with the steps of the free water absorption method in the code for rock tests of water resources and hydropower engineering (SL264-2001), firstly 1/3 of the height of the specimen was injected water, then after $12 \mathrm{~h}$ about $2 / 3$ of the height could be immersed in it, and after $12 \mathrm{~h}$ the whole height of the specimen could be immersed. It was soaked for 30 days, then a watersaturated specimen was prepared. Finally, there were three natural air-dried and watersaturated specimens for conventional static and 18 natural air-dried and water-saturated impact specimens.

\section{Test Results and Analysis}

\subsection{Mechanical Properties of Static Water-Saturated Granite}

In order to compare and analyze the strength of water-saturated granite under static and dynamic loading conditions, the static uniaxial compression tests of natural air-dried and water-saturated granite were carried out on an Instron1346 elector-hydraulic servo controlled testing machine with a measuring range of $2000 \mathrm{kN}$. The loading strain rate was $10^{-5} \mathrm{~s}^{-1}$, and the typical static stress-strain curves of granite specimens under two water states were obtained. The average static compressive strength of granite in a natural dry state is $172 \mathrm{MPa}$ and that of water-saturated rock is $91 \mathrm{MPa}$. This shows that the static strength of rock is greatly affected by water. The static strength of water-saturated granite is significantly lower than that in a natural air-dried state, which is consistent with the current research conclusion [21]. The strength of the specimen after water saturation should be reduced by $40-80 \%$. 


\subsection{Impact Test Results and Analysis}

Firstly, the pure punching test was carried out, and the signals obtained from the strain gauge were used to observe whether the elastic incident bar and the elastic transmission bar are in close contact, so as to judge whether the whole test system met the test requirements and whether the waveform obtained was consistent with the basic principle of SHPB, that is, the one-dimensional stress wave principle of the test system and the stress homogenization principle of the specimen.

On this basis, different impact rates were selected to be used on the specimens step by step. Before each impact, we changed the impact speed to obtain the dynamic compressive strength of the specimen under various impact rates as much as possible, so as to provide as many effective data as possible.

As is known, the dynamic strength of materials has a significant strain rate dependence, and the distribution range of the strain rate is wide. The material testing machine and its measurement technology applied to high strain rate $\left(>10^{2} \mathrm{~s}^{-1}\right)$ and low strain rate $\left(\left(10^{-5}-10^{0}\right) \mathrm{s}^{-1}\right)$ have become mature technologies, but there are few studies on the mechanical properties of quasi-brittle materials such as rock under medium strain rate $\left(\left(10^{0}-10^{1}\right) \mathrm{s}^{-1}\right)$. However, in the fields of deep mining engineering and anti explosion design of large underground caverns and structures, the dynamic characteristics of rock materials in the $\left(10^{0}-10^{1}\right) \mathrm{s}^{-1}$ strain rate range must be considered. Its dynamic characteristics are also a key to the analysis of rock engineering. Increasing the diameter of the Hopkinson bar is one of the effective ways to realize medium strain rate loading of rock. The condition of medium strain rate loading could be better realized by the impact bar diameter of $\Phi 75 \mathrm{~mm}$.

This can not only reveal the dynamic strength characteristics of water-saturated rock materials, but also studies the dynamic characteristics of granite under medium strain rate loading. Therefore, the strength characteristics of water-saturated rock and air-dried rock in the range of medium strain rate have been obtained, and then the differences of dynamic strength characteristics between them under the same strain rate loading have been compared.

The water-saturated granite and natural air-dried granite are divided into three groups respectively. The loading rate is changed by adjusting the impact pressure and punch stroke, and the dynamic impact test of the loading rate from low to high is carried out for each batch of specimens in turn. Due to the inherent heterogeneity of rock materials and test system error, the real strain rate of each specimen is not exactly the same under the same loading conditions, so it can only be controlled within a relatively small range. Therefore, statistics were obtained based on the real strain rate and corresponding dynamic strength of each specimen. The typical waveform of rock specimen under a dynamic test is shown in Figure 5.

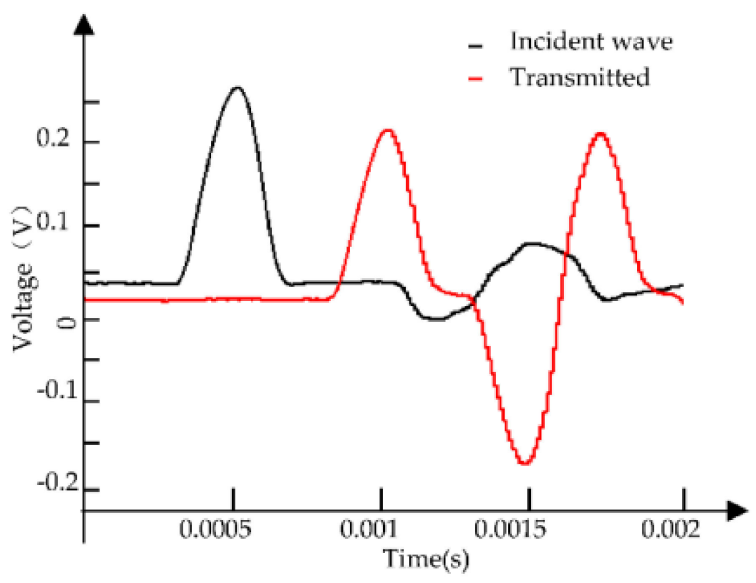

Figure 5. Typical waveform of rock specimen under dynamic test. 
The dynamic strength strain rate curves of natural air-dried and water-saturated granite specimens are shown in Figure 6.

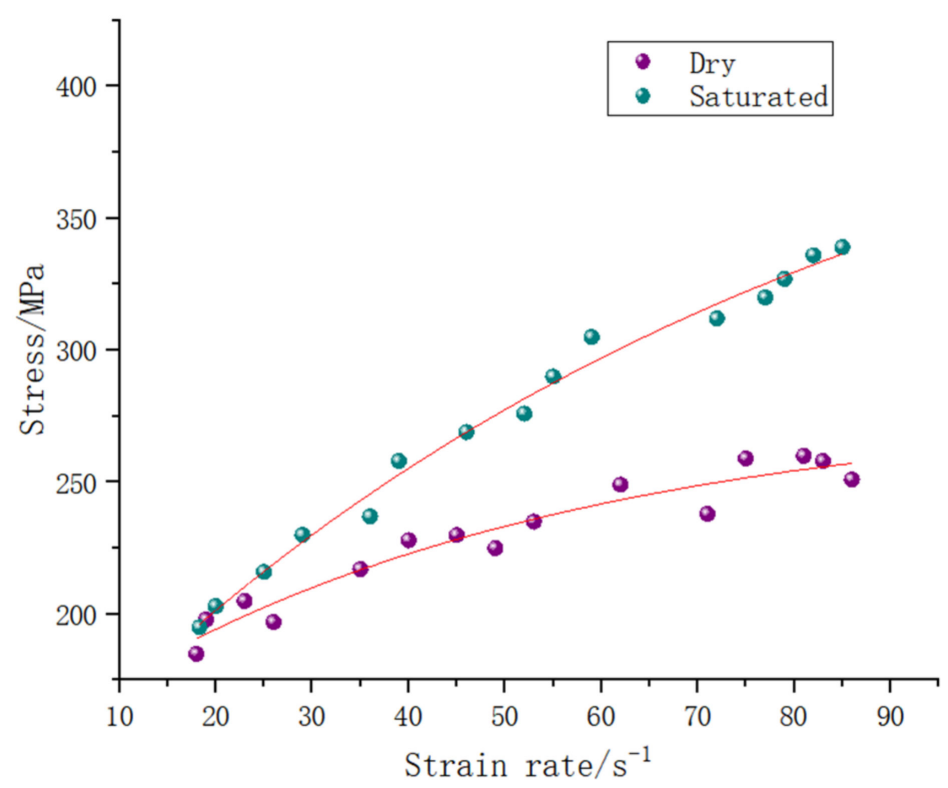

Figure 6. Dynamic strength curves of saturated and air-dried granite.

Due to the heterogeneity of rock materials, even if the specimen selection and processing are strictly controlled, the SHPB test results are much more discrete, which is similar to the research results of strain rate dependence of dynamic characteristics of existing rock materials [22-26].

It can be seen from Figure 6 that within the range of medium strain rate, the variation law of dynamic strength curve of water-saturated granite is similar to that of natural airdried granite, and the strain rate effect is obvious, which is contrary to the result of strength reduction of water-saturated granite under static load. The dynamic strength of air-dried and water-saturated granite fluctuates in varying degrees in the range of the medium strain rate. Considering that the rock dynamic strength will increase [27-29] under the condition of high strain rate, the fitting curve of the two test data shows an upward trend, and there will be some errors in the curve fitting to the data points in the range of $\left(10^{0}-10^{1}\right) \mathrm{s}^{-1}$.

Furthermore, it can be seen from Figure 6 that the water-saturated granite has these following characteristics. The dynamic curve shape of water-saturated granite is similar to that of natural air-dried granite. Under the condition of medium strain rate, the dynamic strength of natural air-dried granite can be increased by nearly 0.5 times compared with its static state (when the strain rate is $85 \mathrm{~s}^{-1}$ ), and the dynamic strength of water-saturated granite can be increased by nearly 1-2 times compared with its static state, showing a stronger strain rate sensitivity than natural air-dried granite.

Under the same medium strain rate, the failure degree of granite specimens in the same state is similar. However, the compression failure effect of natural and water-saturated granite specimens is different. The failure mode is shown in Figure 7. The impact failure of natural air-dried granite is more crushed, and its fragmentation is obviously less than that of water-saturated rock. This shows that water also has an influence on the granite dynamic failure effect. 


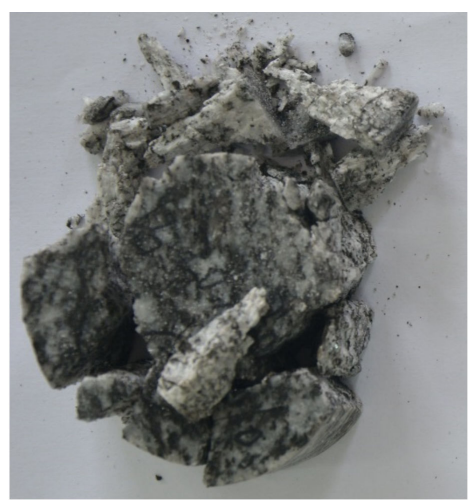

(a)

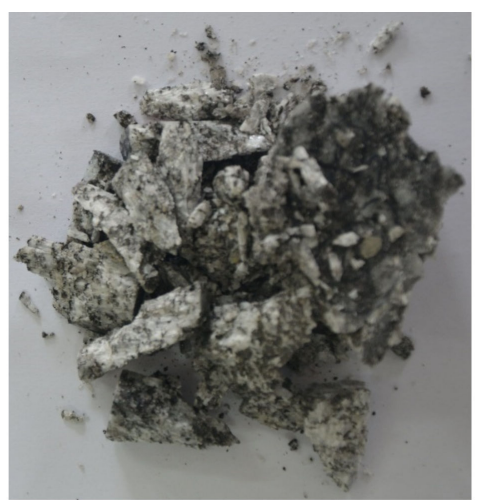

(b)

Figure 7. Failure mode of the granite under different water condition. (a) water-saturated granite (b) natural air-dried granite.

\section{Dynamic Failure Mechanism of Water-saturated Granite}

Whether natural air-dried rock or water-saturated rock, under uniaxial compression static loading, its failure would generally go through five stages, which is pore and crack compaction, elastic deformation, micro crack nucleation, stable development of a micro crack, and overall instability and failure of the specimen caused by rapid crack penetration. For dynamic loading conditions, the increase of loading strain rate would not change this basic fracture mode [30-32]. Within the stable development stage of a micro fracture, water-saturated rock would appear to have inelastic deformation and volume expansion, which is due to the damage of free water existed in pore and crack.

\subsection{Meniscus Effect}

Under static loading, as the crack propagation speed is much faster than the test loading speed, the saturated fluid has enough time to diffuse to the expansion crack. At the same time, free water reaches the crack tip in the expansion crack and can lubricate the crack contact surface to a certain extent, so as to promote the brittle micro fracture activity in the rock and accelerate crack propagation. However, a large number of impact fracture theories and tests show that the rock is destroyed under the action of tensile stress at the crack tip [9]. While under dynamic loading conditions, the crack dynamic propagation speed is faster than the static propagation speed, and the fluid in the rock cannot diffuse into the crack that has just completed expansion. Water will form a bonding force that hinders crack propagation on the crack surface because it is affected by the surface tension of free water, resulting in the fracture of water-saturated rock occurring under high strength, as shown in Figure 8.

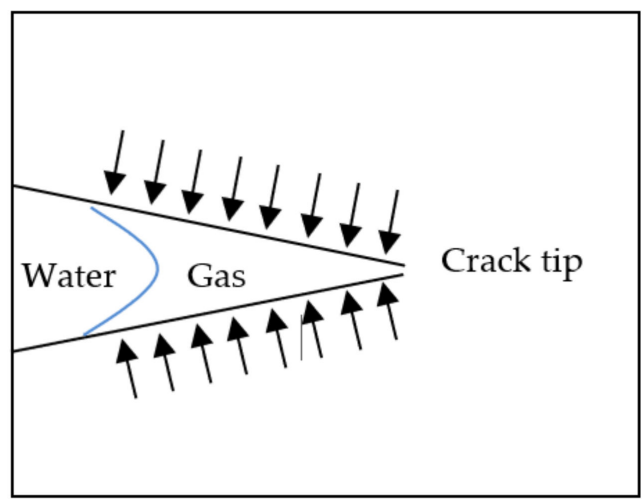

Figure 8. Meniscus effect of fluid. 
It is believed that the bonding force of saturated concrete formed by the surface tension of free water can be expressed as [6],

$$
F=\frac{V \gamma}{2 \rho^{2} \cos \theta}
$$

where, $V$ is the liquid volume, $\gamma$ is the surface energy, $\theta$ is the wetting angle, and $\rho$ is the meniscus radius of water.

\subsection{Bernoulli Effect}

According to the Bernoulli effect, the greater the velocity of water or gas, the smaller the pressure it receives. Similarly, the smaller the speed, the greater the pressure, which are two dialectical factors. As shown in Figure 9, for areas a-b with large storage space of gas and water, the movement speed of water and gas medium is relatively small, the pressure is relatively large, and its effect on surrounding rock medium is also large, which can be defined as $F_{1}$. For the area o-b with small occurrence space, the force $F_{2}$ on the surrounding rock medium is relatively small. However, the force contained in the surrounding rock medium on the newly growing crack could be considered to be evenly distributed along the whole region of $\mathrm{a}-\mathrm{b}-\mathrm{o}$, which can be defined as $F_{0}$.

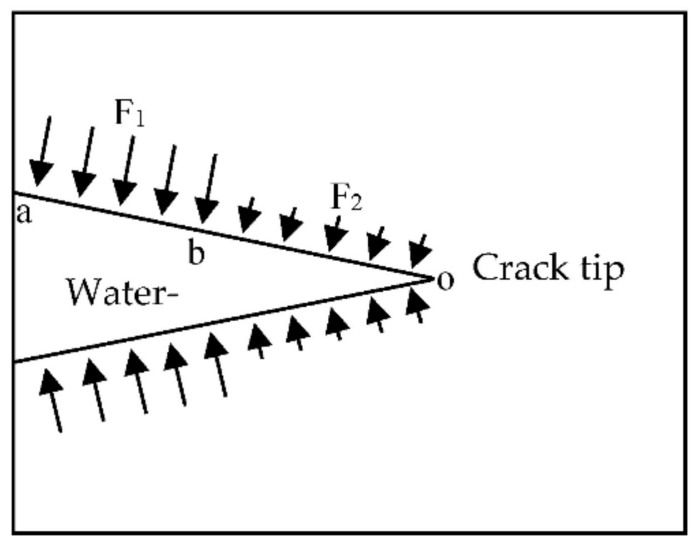

Figure 9. Bernoulli effect of fluid.

When the fluid medium moves faster, the Bernoulli effect is more significant, and there will be $F_{2}<<F_{0}$, which inhibits the further derivation of cracks.

\subsection{Stefan Effect}

The reason for the wet concrete strength increasing under dynamic loading can be explained by the Stefan effect in physics, as shown in Figure 10. Assuming that there is viscous liquid at the crack tip, and the surface area of the crack surface is $S$. A reaction force $F^{\prime}$ will be generated to prevent the propagation and separation of the two sides when the crack surface fractures at the relative speed $d v / d t$, that is, the Stefan effect [33]. The reaction force caused by the Stefan effect can be expressed as,

$$
F^{\prime} \propto \frac{\eta S}{\bar{h}} \frac{d v}{d t}
$$

where, $\eta$ is the viscosity of the liquid (Pa.s), $\bar{h}$ is the equivalent distance between the two crack surfaces, and $v$ is the relative separation velocity of the two cracked surfaces. 


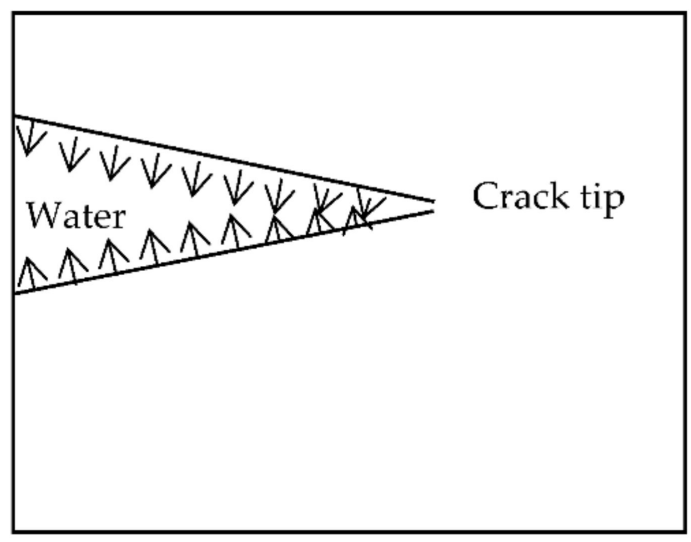

Figure 10. Stefan effect of fluid.

Compared with air-dried rock, there is liquid water in the cracks of water-saturated rock. According to linear fracture mechanics, the crack propagation rate is faster under dynamic conditions. At this time, the Stefan effect of water-saturated rock can hinder its fracture failure.

Through the above analysis, it can be concluded that there is an obvious contrast between the dynamic and static compression failure of natural air-dried and water-saturated granites, indicating that water plays a decisive role in the rock failure process under dynamic loading, and the failure mechanism is completely different from that under static loading.

\section{Conclusions}

Using the SHPB device of $\Phi 75 \mathrm{~mm}$ bar, the dynamic compression strength of Beijing Fangshan granite in the range of medium strain rate under natural air-dried and water saturation has been studied. According to the impact results and analysis, the following conclusions can be obtained:

(1) The dynamic compression strength of water-saturated granite under impact loading is higher than that of air-dried granite, which is contrary to the result that the compression strength of water-saturated rock is lower than that of air-dried rock under static loading.

(2) Under the condition of medium strain rate, the dynamic strength of natural air-dried granite could be increased by nearly 0.5 times compared with its static state (when the strain rate is about $85 \mathrm{~s}^{-1}$ ), and the dynamic strength of water-saturated granite can be increased by nearly 1-2 times compared with its static state, which shows stronger strain rate sensitivity than natural air-dried granite.

(3) The Bernoulli effect of fluid, the adhesion effect of free water and the Stefan effect of fluid in water-saturated granite have been revealed separately. These above effects are the essential reason affecting the dynamic strength of water-saturated granite from the perspective of water-bearing occurrence.

It should be noted that the variation law of different mechanical parameters of watersaturated granite has not been studied in depth, and its physical mechanism has not been fully revealed. At the same time, the dynamic failure characteristics of rock under different water content levels still need to be further studied from the aspects of theory and experiment.

Author Contributions: K.M. contributed to the conception of the study and wrote the manuscript; X.L. helped perform the analysis with constructive discussions; Z.S. contributed significantly to analysis and manuscript preparation; Z.L., R.L., L.W. and Z.C. performed the experiment and the data analyses. All authors have read and agreed to the published version of the manuscript.

Funding: This work was supported by the National Natural Science Foundation of China [Grant No.s 51522903, 51774184], Excellent project Fund in North China University of Technology [Grant No. 
216051360020XN199/006] and Scientific Research Fund in North China University of Technology [Grant No. 110051360002]

Institutional Review Board Statement: Not applicable.

Informed Consent Statement: Not applicable.

Data Availability Statement: The data that support the findings of this study are available from the corresponding author, upon reasonable request.

Conflicts of Interest: The authors declare no conflict of interest.

\section{References}

1. Zhang, Y. Rock Hydraulics and Engineering; China Water Power Press: Beijing, China, 2005. (In Chinese)

2. Grant, A.G. Fluid effect on velocity and attenuation in sandstone. J. Acoust. Soc. Am. 1994, 96, 1158-1173.

3. Laurent, L.; Christian, D.; Philippe, R. Comparison of the anisotropic behavior of undeformed sandstones under dry and saturated conditions. Tectonophysics 2003, 370, 193-212.

4. Zhang, Q.B.; Zhao, J. A review of dynamic experimental techniques and mechanical behaviour of rock materials. Rock Mech. Rock Eng. 2014, 47, 1411-1478. [CrossRef]

5. Li, T.; Du, Y.; Wan, X.; Xi, D. Responses of saturated rocks to mean stress and dynamic stress amplitude. Chin. J. Rock Mech. Eng. 2008, 27, 161-168. (In Chinese)

6. Wang, H.; Li, Q. Micro-mechanism of static and dynamic strengths for saturated concrete. J. Hydraul. Eng. 2006, 37, 958-962. (In Chinese)

7. Liu, G.; Zhou, F. Relation between pore liquid pressures and bulk elastic modulus of loaded saturated rock of low permeability. Chin. J. Rock Mech. Eng. 2004, 23, 1792-1796. (In Chinese)

8. Erguler, Z.A.; Ulusay, R. Water-induced variations in mechanical properties of clay-bearing rocks. Int. J. Rock Mech. Min. Sci. 2009, 46, 355-370. [CrossRef]

9. Li, X.; Gu, D. Rock Impact Dynamics; Central South University of Technology Press: Changsha, China, 1994. (In Chinese)

10. Li, X.; Zhou, Z.; Lok, T.S.; Hong, L.; Yin, T. Innovative testing technique of rock subjected to coupled static and dynamic loads. Int. J. Rock Mech. Min. Sci. 2008, 45, 739-748. [CrossRef]

11. Zuo, Y.J.; Li, X.B.; Zhou, Z.L.; Ma, C.D.; Zhang, Y.P.; Wang, W.H. Damage and failure rule of rock undergoing uniaxial compressive load and dynamic load. J. Cent. South Univ. Technol. 2005, 12, 742-748. [CrossRef]

12. Zhang, Z.X.; Yu, J.; Kou, S.Q.; Lindqvist, P.A. Effects of high temperatures on dynamic rock fracture. Int. J. Rock Mech. Min. Sci. 2001, 38, 211-225. [CrossRef]

13. Ruhbin, A.M.; Ahrens, T.J. Dynamic tensile-failure-induced velocity deficits in rock. Geophys. Res. Lett. 1991, 18, 219-222. [CrossRef]

14. Lou, W. Dynamic fracture behaviour of dry and waterlogged granite. Explos. Shock. Waves 1994, 14, 249-254. (In Chinese)

15. Nikolaevskiy, V.N.; Kapustyanskiy, S.M.; Thiercelin, M.; Zhilenkov, A.G. Explosion dynamics in saturated rock sand solids. Transp. Porous Media 2006, 65, 485-504. [CrossRef]

16. Lin, Y.; Wang, L.; Ding, Y.; Jiang, J.; Sun, F.; Zhang, B.; Liu, Z. Experimental study of damage and fracture zone in cement specimen subjected to exploding wave. Explos. Shock. Waves 2008, 14, 249-254. (In Chinese)

17. Deng, X.F.; Zhu, J.B.; Chen, S.G.; Zhao, Z.Y.; Zhou, Y.X.; Zhao, J. Numerical study on tunnel damage subject to blast-induced shock wave in jointed rock masses. Tunn. Undergr. Space Technol. 2014, 43, 88-100. [CrossRef]

18. Li, D.; Wong, L.N.Y. The Brazilian disc test for rock Mechanics applications: Review and new insights. Rock Mech. Rock Eng. 2013, 46, 269-287. [CrossRef]

19. Man, K.; Song, Z.; Liu, X. Dynamic tensile test of granite and its tensile sensitivity. Adv. Civ. Eng. 2020, 2020, 8837865. [CrossRef]

20. Industry Standard Compilation Group of the People's Republic of China. Code for Rock Test of Water Resources and Hydro Power Engineering (SL264-2001); China Water Resources and Hydro Power Press: Beijing, China, 2001.

21. Li, Y.; Zhu, W.; Bai, S.; Yang, C. Uniaxial experimental study on rheological properties of granite under air-dried and saturated states. Chin. J. Rock Mech. Eng. 2003, 22, 1673-1677.

22. Yilmaz, I. Influence of water content on the strength and deformability of gypsum. Int. J. Rock Mech. Min. Sci. 2010, 47, 342-347. [CrossRef]

23. Vásárhelyi, B.; Ván, P. Influence of water content on the strength of rock. Eng. Geol. 2015, 84, 70-74. [CrossRef]

24. Li, X.B.; Lok, T.S.; Zhao, J. Dynamic characteristics of granite subjected to intermediate loading rate. Rock Mech. Rock Eng. 2005, 38, 21-39. [CrossRef]

25. Wong, L.N.Y.; Ming, C.J. Water saturation effects on the brazilian tensile strength of gypsum and assessment of cracking processes using high-speed video. Rock Mech. Rock Eng. 2014, 47, 1103-1115. [CrossRef]

26. Hashiba, K.; Fukui, K. Effect of water on the deformation and failure of rock in uniaxial tension. Rock Mech. Rock Eng. 2015, 48, 1751-1761. [CrossRef]

27. Zhou, Z.; Cai, X.; Cao, W.; Li, X.; Xiong, C. Influence of water content on mechanical properties of rock in both saturation and drying processes. Rock Mech. Rock Eng. 2016, 49, 3009-3025. [CrossRef] 
28. Li, X.B.; Zhou, Z.L.; Zhao, F.J. Rock properties under coupled static-dynamic loads. J. Rock Mech. Geotech. Eng. $2009,1,41-47$. [CrossRef]

29. Olsson, W.A. The compressive strength of tuff as a function of strain rate from $10^{-6}$ to $10^{3} /$ sec. Int. J. Rock Mech. Min. Sci. Geomech. Abstr. 1991, 28, 115-118. [CrossRef]

30. Wang, B.; Li, X.; Yin, T.; Ma, C.; Yin, Z.; Li, Z. Split hopkinson pressure bar(SHPB) experiments on dynamic strength of water-saturated sandstone. Chin. J. Rock Mech. Eng. 2010, 29, 1003-1009.

31. Zhang, Q.B.; Zhao, J. Effect of loading rate on fracture toughness and failure micromechanisms in marble. Eng. Fract. Mech. 2013, 102, 288-309. [CrossRef]

32. Rossi, P.; Van Mier JG, M.; Boulay, C.; Le Maou, F. The dynamic behavior of concrete: Influence of free water. Mater. Struct. 1992, 25, 509-514. [CrossRef]

33. Zheng, D.; Li, Q.B. An explanation for rate effect of concrete strength based on fracture toughness including free water viscosity. Eng. Fract. Mech. 2004, 71, 2319-2327. [CrossRef] 